\title{
Impact of catheter and surgical ablation on arrhythmia treatment in a tertiary referral centre
}

\author{
David Cunningham, Edward Rowland
}

\begin{abstract}
Invasive cardiac electrophysiology studies began as diagnostic studies. The past decade has seen the introduction of several new treatments which have broadened the scope of invasive electrophysiology studies. In particular, the development of catheter ablation techniques increasingly allows curative treatment to be delivered in the catheter laboratory.

The workload of electrophysiological procedures has steadily increased in our tertiary referral centre. Over 1000 patients have been treated in the past 20 years and it is projected that 219 new patients will be treated in 1991 and 342 procedures will be carried out. Over $25 \%$ of patients now receive either catheter or surgical ablation and almost $80 \%$ of these are cured permanently without the need for further drug treatment. The development of safer techniques for catheter ablation has led to its increased use and a decline in surgical ablations. Because catheter ablation is a much simpler and less traumatic procedure than surgical ablation there are great advantages both for the patient and in terms of costeffectiveness. Antitachycardia pacing, relatively common in 1985 , has now largely been supplanted by ablation and implantation of defibrillators.
\end{abstract}

As the tendency to non-pharmacological treatment increases and evidence mounts that cost-effectiveness is greater for electrophysiological treatments, the implications for the funding of electrophysiology services grow. The initially high cost of curative treatment needs to be balanced against the longer term and potentially higher costs of palliative drug treatment. The potential to cure patients with catheter procedures may lead to a greater demand for this expertise and a need for an increase in training and facilities.

The investigation of cardiac arrhythmias was revolutionised by the introduction of invasive electrophysiological (EP) methods in the late

1960s which clarified mechanisms of arrhyth- mia and the methods by which accessory pathways and reentrant circuits could be localised. The role of electrophysiological studies became established as a method of confirming the arrhythmia mechanism and substrate, testing antiarrhythmic medications, and as a prerequisite for surgical ablation or implantation of an antitachycardia pacemaker.

Therapeutic options have been extended by the availability of cardiac transplantation and implantable cardioverter-defibrillators. However, because of the advent of catheter ablation in the $1980 \mathrm{~s}^{1}$ the role of the electrophysiological study itself has become extended into a directly therapeutic procedure, with implications for the treatment of a wide variety of cardiac arrhythmias.

We have reviewed the numbers of patients treated by invasive electrophysiological procedures and in particular the trend towards curative treatment and away from drug treatment over the past six years in a tertiary referral centre with a specialist cardiac electrophysiological service.

\section{Methods}

The first electrophysiological study was performed in the National Heart and Brompton Hospitals in March 1971. These hospitals functioned as a secondary and tertiary referral centre supplying a wide range of cardiological services to many health authorities. Since 1971 over 1000 patients have undergone more than 1400 invasive procedures for the diagnosis, control, or cure of cardiac arrhythmias. The number remained small until mid 1984, when a full-time clinician with an interest in arrhythmias was appointed. Since then both the number of procedures and the treatments used have grown steadily, though a temporary reduction was seen during 1989-90 when the hospitals amalgamated (to form the Royal Brompton National Heart and Lung Hospital, Chelsea) and laboratory access was temporarily restricted. These restrictions ended in December 1990.

The number and type of invasive electrophysiological procedures performed from 3 March 1971 to 9 May 1991 was obtained from the following sources: (a) a computerised database of all catheter laboratory procedures in the Brompton and National Heart Hospitals
Brompton National Heart

and Lung Hospital, Sydney Street, London SW3 6NP.

Accepted for publication 4 October 1991 
(currently held in Orchids ${ }^{\star}$ database on an inhouse Hewlett Packard 9000 supermini computer); (b) a log book of all invasive procedures (maintained by the pacing and electrophysiology physiological measurement technicians); and ( $c$ ) a computerised database of all ablative and implantable device procedures (held in the EPSt database on MS-DOS 386 desktop computers).

All data from all sources were coded by a unique hospital number. The data were extracted from the computerised sources and imported into a Lotus 1-2-3 spreadsheet running on a 386-compatible desktop computer. The outcome and complication data for the ablation procedures were provided by in-built report generators in EPS.

The types of electrophysiological procedure were classified as follows:

(a) Diagnostic-To provoke and study mechanisms of clinical arrhythmia and assess the effects of pharmacological or nonpharmacological treatment.

(b) Flutter conversion-To convert spontaneously occurring atrial flutter.

(c) Antitachycardia pacemaker implant.

(d) Catheter ablation.

(e) Surgical ablation.

(f) Implantable cardioverter defibrillator implant.

In addition, each procedure was classified as primary if performed on a patient who had had no previous invasive electrophysiological procedure of any kind or secondary if preceded by an electrophysiological procedure of any kind. Thus most procedures of types $(c)$ to $(f)$ (above) were secondary, because they were preceded by a diagnostic electrophysiological study. Similarly, restudy after ablation or drug treatment was a secondary procedure. The total number of primary procedures is the same as the number of new patients.

Any secondary procedures carried out at the bedside are not recorded in the sources listed above and are therefore not included in this study. These account for a significant number of repeat electrophysiological procedures carried out on patients undergoing serial electrophysiological-guided drug testing (via single wires left in situ after primary electrophysiological study) and on patients tested after sugical ablation (via epicardial wires placed at operation). We recognise that the number of procedures recorded under "diagnostic electrophysiological study" will be an underestimate.

To place the 1991 workload in the context of previous years, the number of procedures from

*Orchids (Oracle-based Relational Cardiology Hospital Information Database System) is a distributed relational database mation Database System) is a distributed relational database developed to run under Oracle by Dr A F Rickards at the Royal Brompton National Heart and Lung Hospital. It can run on mainframe, mini, or personal computers. Currently, Orchids covers all in-patient cardiological data with the exception of invasive electrophysiological procedures, which is a planned future expansion.

†EPS is a stand alone relational database running on individual desktop computers. It was developed under Dataease by Dr A D Cunningham at the Royal Brompton National Heart and Lung Hospital and can transfer data to Orchids if necessary. It allows storage of overview data for all invasive electrophysiological procedures, with in depth modules covering catheter and surgical ablation.
1 January 1991 to 9 May 1991 was extrapolated to provide a figure for the whole of 1991 , based on the number of working days available in the laboratory and taking into account the possible exaggeration caused by any backlog that had built up by the end of 1990 .

\section{Results}

ALL ELECTROPHYSIOLOGICAL PROCEDURES

In the 20 year period March 1971-May 1991, 1009 patients had 1428 invasive electrophysiological procedures. Figures 1 and 2 show the annual number of procedures and new patients. The mean number of patients and procedures per year between 1971 and 1983 (inclusive) was 10 and 11 respectively. These figures increased to 110 and 165 between 1984 and the end of 1990, and correspond to the appointment of a full-time cardiac electrophysiologist. At the time of writing, we project that in 1991, after the opening of a dedicated laboratory, we will treat 219 new patients and undertake 342 procedures.

Before 1984 all electrophysiological procedures were diagnostic with the exception of two antitachycardia pacemaker implants. Catheter ablation was introduced in 1984, surgical ablation and flutter conversion in 1985, and an implantable defibrillator implant in 1988. Antitachycardia pacemaker implants were increased from 1985 onwards. Figure 3 shows the breakdown of the total electrophysiological procedures into the six specific types. Table 1 shows the data for primary and secondary procedures in these types.

\section{ABLATIVE PROCEDURES: NUMBERS}

Figure 4 shows the percentage of new patients undergoing all ablative procedures since their introduction. This increased steadily from 1985, until ablative procedures represented $>30 \%$ of all procedures in 1989 and 1990 . In 1991 the figure dropped to just under $25 \%$. Inspection of aggregate figures in table 1 showed that the total number of ablations continued to rise in 1991, but there was a drop in diagnostic electrophysiological studies in 1989-90 with no decrease in ablative procedures.

Figure 5 shows the numbers of catheter and surgical ablations. Although it was introduced to these hospitals a year earlier, catheter ablation was rapidly overtaken by surgical ablation from 1985 to 1988 . In 1988 , the number of surgical ablations was nearly double the number of catheter ablations. There was a sharp reversal from 1989 to the present day, with increasing numbers of catheter procedures at the expense of surgical ablations. At present, there are three times as many catheter ablations as surgical ablations.

Catheter ablation of ventricular tachycardia remains at a relatively low level (a total of 21 procedures between 1985 and the end of 1990) like surgical ablations of ventricular tachycardia in the same period. ${ }^{20}$ In contrast, ablation of supraventricular tachycardia has become increasingly successful with catheter techniques, and we project that 48 procedures will 


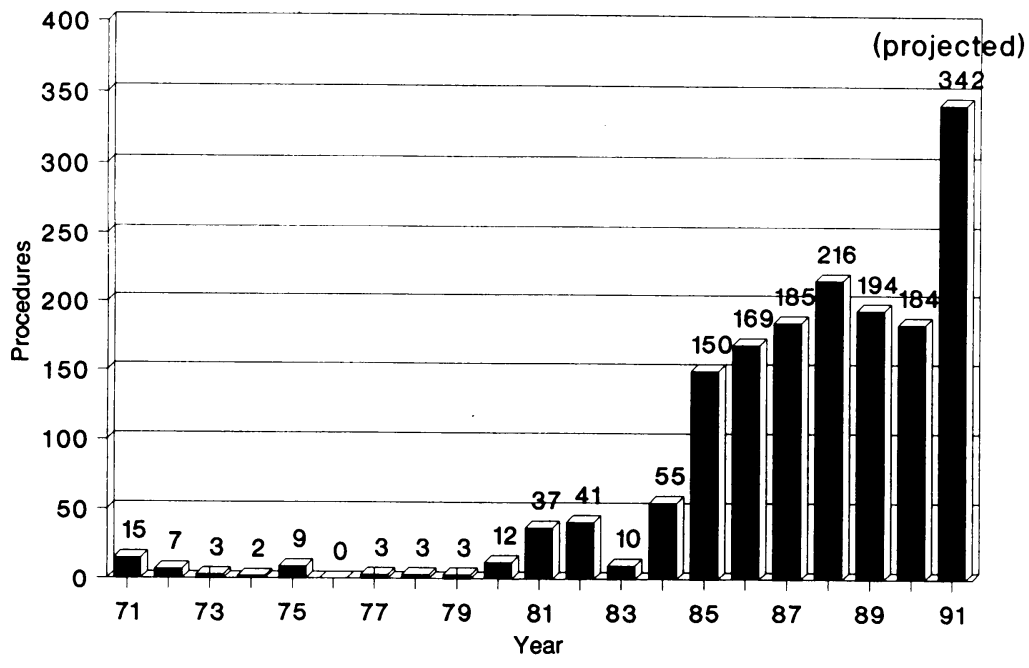

Figure 1 Annual number of procedures between 1971 and 1991. There was a considerable increase after the appointment of a full-time electrophysiologist in 1984. Figures for 1991 are projected from current workload.

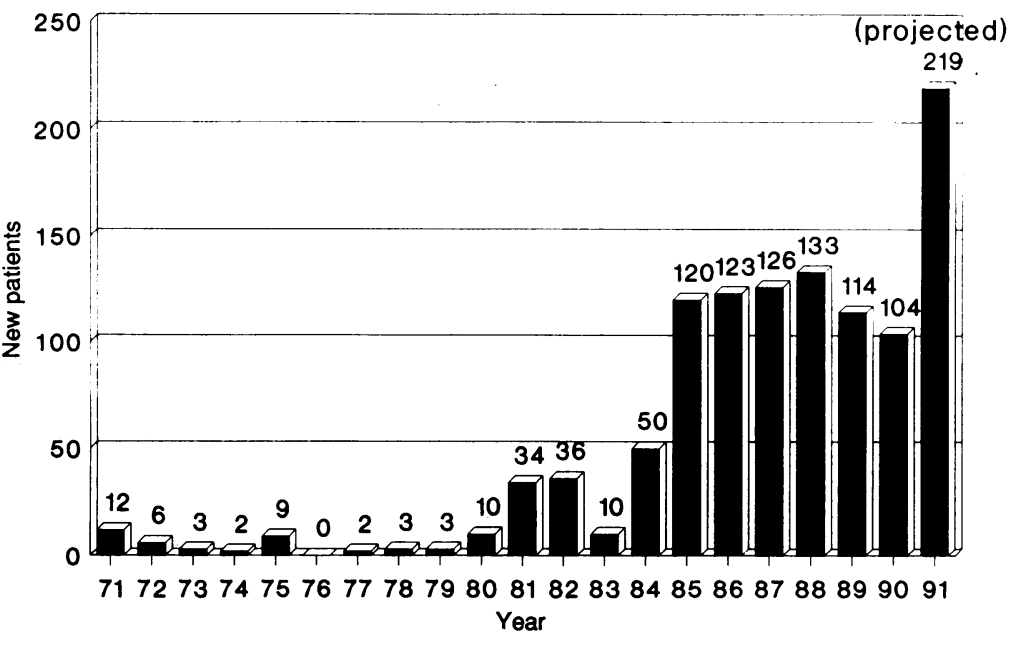

Figure 2 Number of patients per year treated for the first time with invasive electrophysiological procedures. Workload increased steadily since 1984 apart from artificial restrictions in 1989-90 (see text).

Figure 3 Breakdown of procedures from 1983 to 1991 shows the steady rise in catheter ablations, the increase in antitachycardia pacemakers and sugical ablations from 1985 to 1988 which has now been reversed, and the slow emergence of implantation of cardioverter| defibrillators. be performed by a catheter technique in 1990 compated with 16 by a surgical one. This compares with eight catheter and 23 surgical procedures in 1988.

OTHER FORMS OF NON-PHARMACOLOGICAL TREATMENT

Antitachycardia pacing was at its peak in 198789 , and was used almost exclusively as a treatment for atrioventricular nodal reentrant tachycardia. Only one patient has had a device implanted since 1989. (This was a patient with slow ventricular tachycardia which could not be ablated by catheter. Because the patient was not a suitable candidate for any surgical procedure owing to very poor left ventricular function, the pacemaker was implanted as a last resort. The patient's ventricular tachycardia was controlled but he died of progressive heart failure nine months later.) Since 1988, implantable cardioverter/defibrillators have increased slowly. A total of 13 patients have currently been implanted with 14 devices.

Two patients in our series received a cardiac transplantation for severe cardiomyopathy complicated by intractable ventricular tachycardia and ventricular fibrillation.

\section{PATIENT FLOW}

Figure 6 shows the treatment received by the 1009 patients who underwent invasive electrophysiological procedures: 776 were either treated with drug treatment alone or did not require treatment. The remaining 233 had some form of interventional procedure. There is a complex flow of patients between the forms of non-pharmacological treatment, but several points are worthy of note.

(a) Forty one patients were referred directly for catheter ablation without a primary diagnostic electrophysiological study. Most of these underwent ablation of atrioventricular conduction for control of drug-refractory atrial fibrillation or flutter.

(b) In the last year, however, an increasing number of patients have had a diagnostic electrophysiological study for atrioventricular nodal reentrant tachycardia or atrioventricular reentrant tachycardia and have progressed immediately to catheter ablation.

(c) Sixty nine patients were referred for catheter ablation after a primary electrophysiological study and two had a flutter conversion procedure before catheter ablation.

(d) Of 114 patients referred for catheter ablation, $13(11 \%)$ subsequently underwent surgical ablation.

(e) Two patients who underwent surgical ablation before 1990 have recently had catheter ablations. One had successful surgical ablation of ventricular tachycardia but after 18 months presented with a new clinical ventricular tachycardia which was successfully ablated by catheter. The second patient initially had an excellent result after surgical ablation of an anteroseptal accessory pathway and simultaneous cryosurgical modification of a slow atrioventricular nodal pathway for cure of atrioventricular nodal reentrant tachycardia. Atrial flutter then occurred three months 
Table 1 Annual workloads for invasive electrophysiology procedures

\begin{tabular}{|c|c|c|c|c|c|c|c|c|c|c|c|c|}
\hline \multirow[b]{2}{*}{ Year } & \multicolumn{2}{|c|}{ Diagnostic } & \multicolumn{2}{|c|}{$\begin{array}{l}\text { Flutter } \\
\text { conversion }\end{array}$} & \multicolumn{2}{|c|}{$\begin{array}{l}\text { Antitachycardia } \\
\text { pacemaker }\end{array}$} & \multicolumn{2}{|c|}{$\begin{array}{l}\text { Catheter } \\
\text { ablation }\end{array}$} & \multicolumn{2}{|c|}{$\begin{array}{l}\text { Surgical } \\
\text { ablation }\end{array}$} & \multicolumn{2}{|c|}{ ICD implan } \\
\hline & $1^{\circ}$ & $2^{\circ}$ & $1^{\circ}$ & $2^{\circ}$ & $1^{\circ}$ & $2^{\circ}$ & $1^{\circ}$ & $2^{\circ}$ & $1^{\circ}$ & $2^{\circ}$ & $1^{\circ}$ & $2^{\circ}$ \\
\hline pre-1984 & 130 & 7 & 0 & 0 & 5 & 3 & 0 & 0 & 0 & 0 & 0 & 0 \\
\hline 1984 & 50 & 0 & 0 & 0 & 1 & 1 & 3 & 0 & 0 & 0 & 0 & 0 \\
\hline 1985 & 115 & 9 & 3 & 0 & 8 & 6 & 7 & 0 & 2 & 0 & 0 & 0 \\
\hline 1986 & 113 & 15 & 4 & 1 & 3 & 1 & 13 & 7 & 12 & 0 & 0 & 0 \\
\hline 1987 & 113 & 33 & 11 & 1 & 3 & 0 & 8 & 3 & 13 & 0 & 0 & 0 \\
\hline 1988 & 122 & 40 & 6 & 2 & 2 & 0 & 13 & 4 & 25 & 0 & 2 & 0 \\
\hline 1989 & 95 & 26 & 6 & 1 & 2 & 0 & 27 & 11 & 21 & 0 & 5 & 0 \\
\hline 1990 & 90 & 26 & 7 & 1 & 3 & 0 & 25 & 7 & 19 & 0 & 4 & 1 \\
\hline 1991 (projected) & 192 & 58 & 11 & 0 & 0 & 0 & 50 & 13 & 16 & 0 & 2 & 0 \\
\hline
\end{tabular}

$1^{\circ}$, primary procedure; $2^{\circ}$, secondary procedure; ICD, implantable cardioverter/defibrillator.

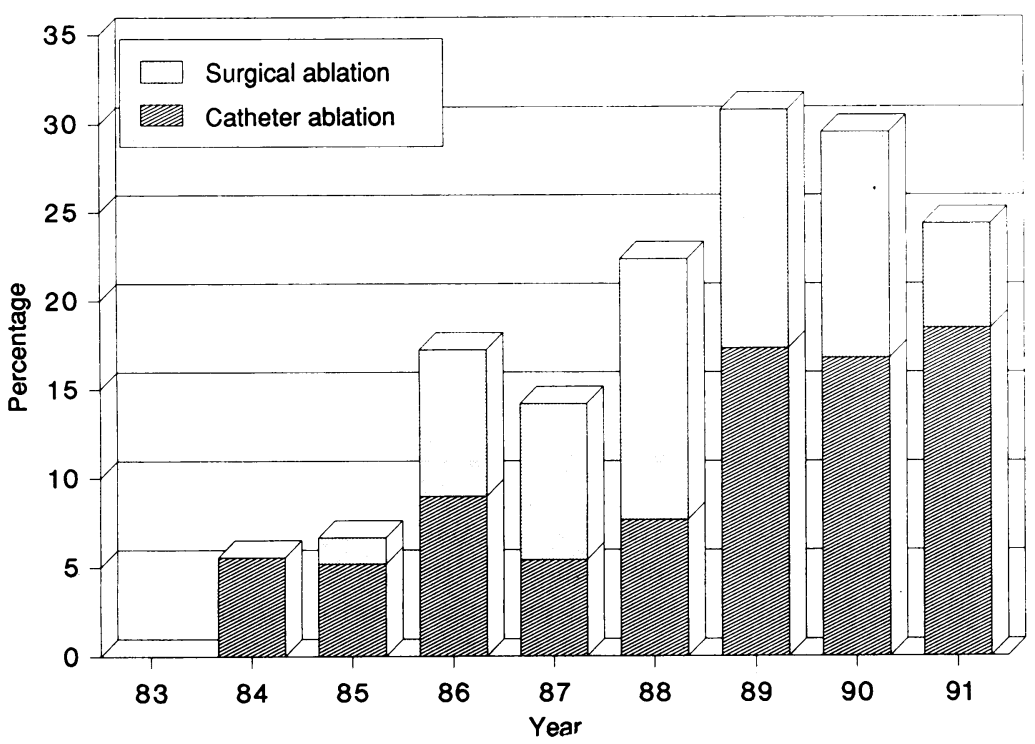

Figure 4 Percentage of patients undergoing definitive ablative treatment increased from zero in 1983 to 30\% in 1989-90. Number of procedures continues to increase in 1991 , although an increase in diagnostic electrophysiological studies reduced the proportion of ablative procedures to $25 \%$.

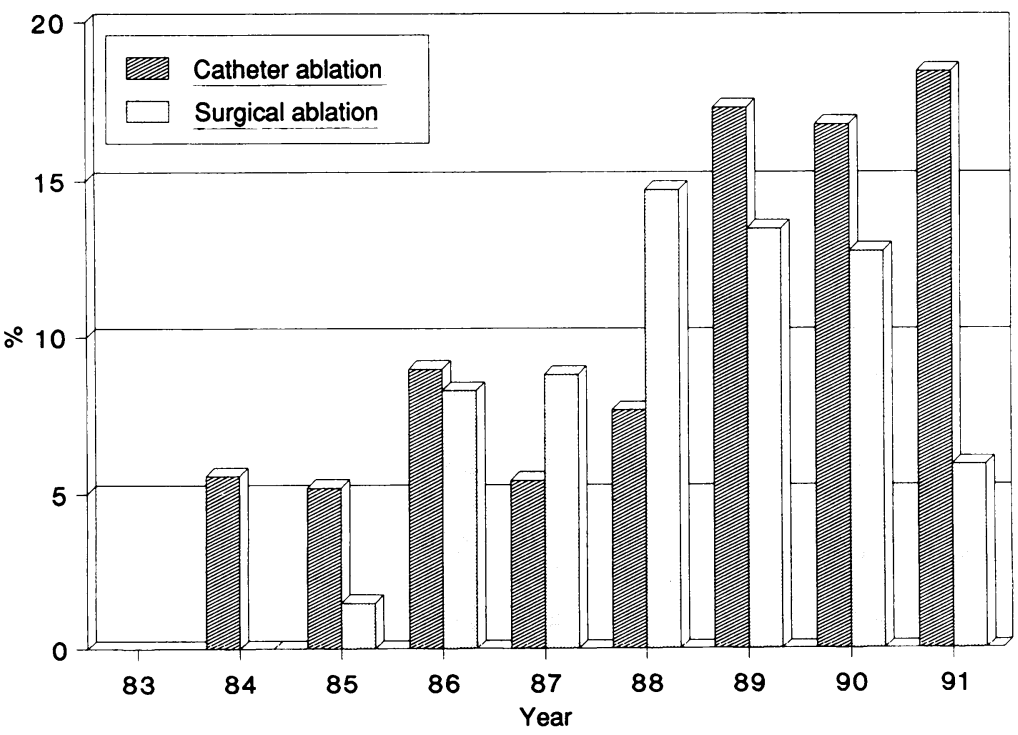

Figure 5 Relative number of patients undergoing catheter or surgical ablation shows surgical procedures overtaking catheter procedures from 1985 to 1988 and then $a$ progressive decline in surgical procedures accompanied by a sharp rise in catheter ablations. postoperatively, and was conducted via the single remaining atrioventricular nodal pathway with intermittent $1: 1$ response. Because the patient remained refractory to medication, catheter ablation was used to create complete heart block. A further patient who failed surgical ablation of an accessory pathway at another United Kingdom centre has also had successful catheter ablation recently.

$(f)$ Of the 12 patients receiving implantable cardioverter/defibrillators, 10 were referred direct from diagnostic electrophysiological study, one had a failed catheter ablation, and one a failed surgical ablation.

(g) Seven hundred and seventy six patients $(77 \%)$ were managed by drug treatment alone or required no treatment. Many of these patients underwent serial electrophysiological testing, although some of these procedures were carried out at the bedside via a single wire left in situ after the primary electrophysiological study. These bedside studies are not included in the procedure numbers in fig 6 .

\section{ABLATIVE PROCEDURES: RESULTS}

One hundred and ninety seven patients had one or more ablative procedures. Ninety nine had 1-4 catheter ablation sessions; 83 had a single surgical ablation session; 13 had surgical ablation after failed catheter ablation; and two had catheter ablation after previous surgical ablation, as discussed above. The overall results were complete cure in $155(79 \%)$, control of arrhythmia by a previously ineffective drug treatment in $10(5 \%)$, failure in $28(14 \%)$, and procedure-related death in three $(1.5 \%)$ ) (table 2).

Tables 3 and 4 show the individual results for catheter and surgical ablation of different arrhythmias. Overall, catheter ablation was successful in $59 \%$, with minimal complications. Surgical ablation had a higher success rate $(89 \%)$ but there were serious complications in $10 \%$. All three surgical failures to divide accessory pathways occurred within the first two years of experience. No patients required a repeat surgical ablation whereas multiple catheter ablation sessions were required in $25.4 \%$ of patients.

\section{Discussion}

FACTORS AFFECTING TOTAL NUMBER OF ELECTROPHYSIOLOGICAL PROCEDURES

As one would expect, there was a major 
Figure 6 Flow of 1009 patients undergoing 1428 invasive

electrophysiological

procedures over a 20 year

period shows that most

patients require no

treatment or only drug

treatment. However, an

increasing number receive

non-pharmacological

treatment, in particular

ablative procedures. Most

of these have had a prior

diagnostic

electrophysiological study but there is a recent trend towards combining the two into a single study. This is both convenient for the patient and highly costeffective. Antitachycardia pacemakers are no longer used, having been replaced by ablation and

implantation of a

cardioverter/defibrillator.

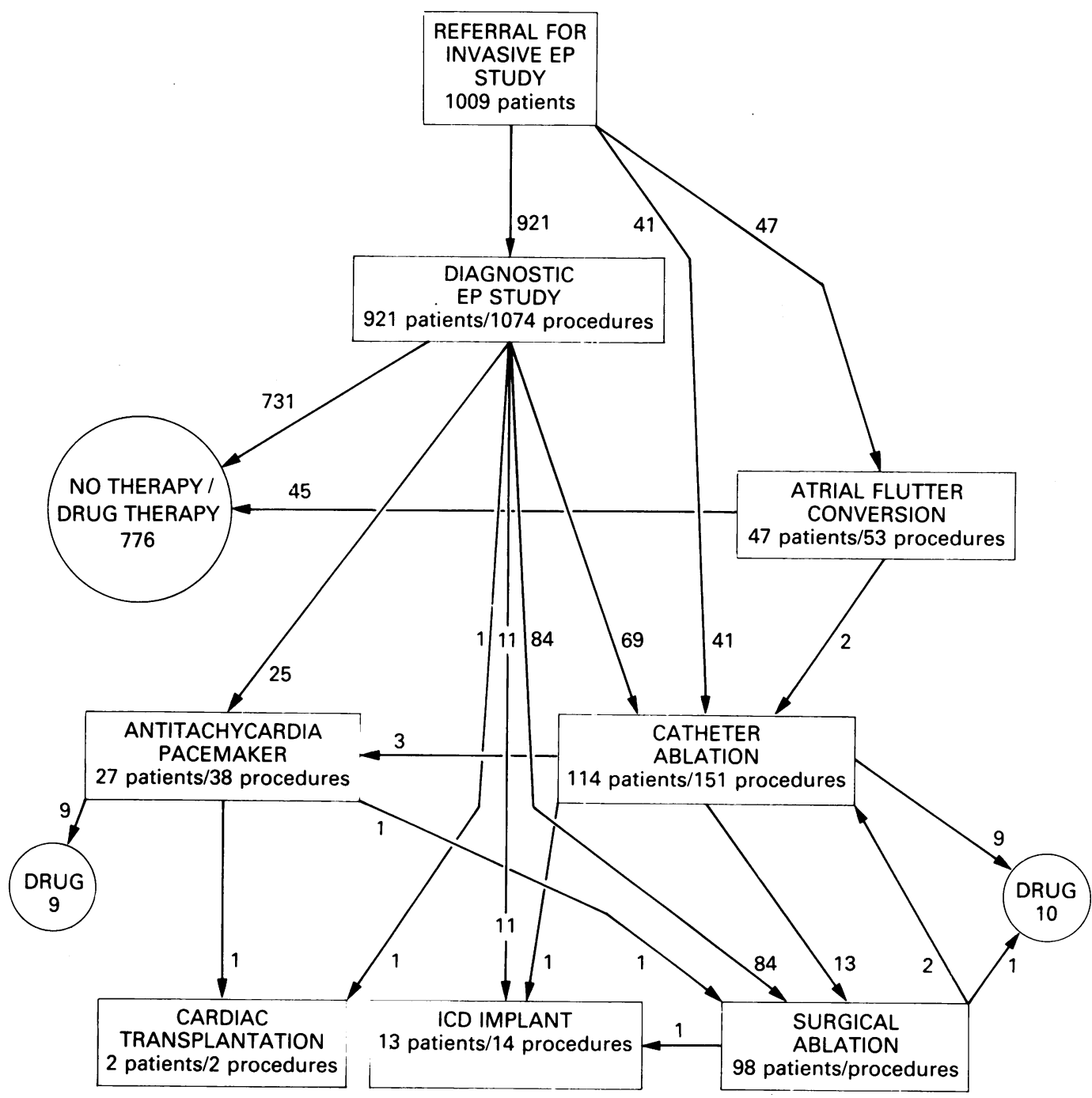

increase in the number of electrophysiological procedures after a full-time cardiac electrophysiologist was appointed midway through 1984. There has also been a progressive increase in total procedures since that time because of increasing clinical demand.

\section{IMPLANTABLE DEVICES}

Antitachycardia pacing was at its peak in 198587 and was used almost exclusively as a treatment for atrioventricular nodal reentrant tachycardia. Since that time, surgical and then catheter techniques have increasingly offered a potential cure for this arrhythmia and have now completely supplanted the use of antitachycardia pacing in our hospital. In patients with ventricular arrhythmias that cannot be controlled by drugs or cured by an ablative procedure, the implantable cardioverter/ defibrillator, with or without an antitachycardia pacing capability, offers a much more

secure treatment than antitachycardia pacing alone, because of risk of tachycardia acceleration. (Many of the present generation of "tiered-therapy" implantable cardioverter/ defibrillator devices incorporate antitachycardia pacing modes as the primary treatment for haemodynamically tolerated ventricular tachycardia, and the future role of the stand alone antitachycardia pacemaker is therefore probably very small in centres such as ours.)

\section{ABLATIVE PROCEDURES}

Table 2 shows that nearly $80 \%$ of patients who were treated by catheter and/or surgical ablation were completely cured without the need for drug treatment. Catheter ablation was used with enthusiasm in its early stages, but some disillusionment with poor results led to its partial decline in $1987-88$, as shown by the relatively higher number of surgical ablations at that time (fig 5). However, improvements in

Table 2 Overall results of ablative procedures

\begin{tabular}{|c|c|c|c|c|c|}
\hline Procedure & $\begin{array}{l}\text { Number of } \\
\text { of patients }\end{array}$ & Cured (\%) & $\begin{array}{l}\text { Controlled by } \\
\text { previously } \\
\text { ineffective drug } \\
\text { treatment (\%) }\end{array}$ & Failed (\%) & $\begin{array}{l}\text { Procedure- } \\
\text { related } \\
\text { death }(\%)\end{array}$ \\
\hline $\begin{array}{l}\text { Catheter ablation alone } \\
\text { Catheter then surgical ablation } \\
\text { Surgical ablation alone } \\
\text { Surgical then catheter ablation } \\
\text { Total }\end{array}$ & $\begin{array}{r}99 \\
13 \\
83 \\
2 \\
197\end{array}$ & $\begin{array}{c}66(67) \\
9(69) \\
78(94) \\
2(100) \\
155(78 \cdot 7)\end{array}$ & $\begin{array}{l}9(9) \\
1(8) \\
0 \\
0 \\
10(5 \cdot 1)\end{array}$ & $\begin{array}{l}24(24) \\
1(8) \\
3(4) \\
0 \\
28(14 \cdot 2)\end{array}$ & $\begin{array}{l}0 \\
2(15) \\
2(2) \\
0 \\
4(2 \cdot 0)\end{array}$ \\
\hline
\end{tabular}




\begin{tabular}{|c|c|c|c|c|c|}
\hline Procedure & $\begin{array}{l}\text { Number of } \\
\text { of patients }\end{array}$ & Cured & $\begin{array}{l}\text { Controlled by } \\
\text { previously } \\
\text { ineffective drug } \\
\text { treatment }\end{array}$ & Failed & $\begin{array}{l}\text { Procedure- } \\
\text { related } \\
\text { death }(\%)\end{array}$ \\
\hline $\begin{array}{l}\text { Accessory pathway } \\
\text { Ventricular tachycardia } \\
\text { Atrial tachycardia } \\
\text { Ablation of AV conduction } \\
\text { Modification of AV conduction } \\
\text { Atrial flutter }\end{array}$ & $\begin{array}{r}38 \\
15 \\
2 \\
52 \\
5 \\
2\end{array}$ & $\begin{array}{r}21 \\
5 \\
0 \\
40 \\
1 \\
0\end{array}$ & $\begin{array}{l}4 \\
3 \\
0 \\
3 \\
0 \\
0\end{array}$ & $\begin{array}{r}13 \\
7 \\
2 \\
9 \\
4 \\
2\end{array}$ & $\begin{array}{l}0 \\
0 \\
0 \\
0 \\
0 \\
0\end{array}$ \\
\hline Total & 114 & $67(58 \cdot 8 \%)$ & $10(8 \cdot 8 \%)$ & $37(32.5 \%)$ & 0 \\
\hline
\end{tabular}

Serious complications (3): coronary sinus rupture (1) (after high energy catheter ablation of posteroseptal accessory pathway in the coronary sinus os. Surgically repaired in catheter laboratory) and ventricular fibrillation (2). AV, atrioventricular.

\begin{tabular}{|c|c|c|c|c|c|}
\hline Procedure & $\begin{array}{l}\text { Number of } \\
\text { of patients }\end{array}$ & Cured & $\begin{array}{l}\text { Controlled by } \\
\text { previously } \\
\text { ineffective drug } \\
\text { treatment }\end{array}$ & Failed & $\begin{array}{l}\text { Procedure- } \\
\text { related } \\
\text { death }(\%)\end{array}$ \\
\hline $\begin{array}{l}\text { Accessory pathway } \\
\text { Ventricular tachycardia } \\
\text { Atrial tachycardia } \\
\text { Ablation of AV conduction } \\
\text { Modification of AV conduction }\end{array}$ & $\begin{array}{r}68 \\
20 \\
4 \\
4 \\
2\end{array}$ & $\begin{array}{r}64 \\
14 \\
3 \\
3 \\
2\end{array}$ & $\begin{array}{l}0 \\
1 \\
0 \\
0 \\
0\end{array}$ & $\begin{array}{l}3 \\
3 \\
0 \\
0 \\
0\end{array}$ & $\begin{array}{l}1 \\
1 \\
0 \\
1 \\
0\end{array}$ \\
\hline Total & 98 & $87(88 \cdot 8 \%)$ & $1(1.0 \%)$ & $6(6 \cdot 1 \%)$ & $3(2 \cdot 9 \%)$ \\
\hline
\end{tabular}

Serious complications (10): procedure-related death (3) (low output state after bypass $(2 \mathrm{~h}$ ) followed by accessory pathway ablation, progressive cardiac failure ( 3 days) followed by VT ablation, septicaemia ( 7 days) followed by ablation of AV conduction); late deaths (1) (sudden cardiac death ( 6 months) followed by VT ablation); severe CVA (2); complete heart block after accessory pathway dissection (1); acute congestive heart failure (1); atrial flutter with 1:1 atrioventricular conduction (1); right leg amputation (1).

AV, atrioventricular, VT, ventricular tachycardia; CVA, cerebrovascular accident.

technology (the development of a low-energy ablation power source ${ }^{2}$ and catheter ${ }^{3}$ and technique (particularly the use of retrograde aortic catheterisation to approach left sided accessory pathways ${ }^{4}$ led to improved results and increased enthusiasm from 1989 onwards. As a result, catheter ablation procedures in the past three years have had a success rate approaching $80 \%$ and now outnumber surgical ablations $3: 1$. Such a ratio is likely to persist or even increase as ablation methods which do not require a general anaesthetic (such as radiofrequency ${ }^{5}$ ) are increasingly used. Radiofrequency ablation was introduced in our hospital in 1990, and our early results suggest that its success rate is comparable to low or high energy DC ablation for accessory pathway ablation. Other workers' experience ${ }^{6}$ suggests that it may be a less useful technique for the creation of a complete heart block or ablation of ventricular tachycardia, but it is probably the technique of choice ${ }^{67}$ for modification of the atrioventricular node in cases of atrioventricular nodal reentrant tachycardia.

Early on, when we were using high energies and conventional pacing catheters for ablation, cardiac tamponade was caused in one patient by rupture of the coronary sinus during attempted ablation of a posteroseptal accessory pathway. This experience and similar reports from other groups gave us the impetus to develop safer methods of catheter ablation. ${ }^{23}$ Our fundamental strategy is to err on the side of safety during catheter ablation, thus making it a safe and reasonably effective procedure, and therefore worth attempting before proceeding to operation in almost all patients. In our practice, it is the treatment of choice for ablation of accessory pathways as well as for the creation of complete heart block, and it remains worth attempting in some selected cases of ventricular tachycardia. Surgical treatment has been preferred to catheter modification of atrioventricular nodal conduction in the treatment of atrioventricular nodal reentrant tachycardia and for ablation of focal atrial ectopic tachycardia. We have, however, begun to gain experience in attempting modification of atrioventricular nodal conduction by multiple applications of radiofrequency energy to the region of the triangle of Koch. Other groups have already reported success with this technique, both with radiofrequency energy ${ }^{78}$ and conventional shocks. ${ }^{9}$ Recently reported results for ablation of accessory pathways by radiofrequency energy $^{81011}$ suggest that this technique may completely replace surgery for this indication in the near future.

COST EFFECTIVENESS OF CATHETER ABLATION

Significant decreases in health care costs have been reported during long-term follow up of patients who have undergone catheter ablation of atrioventricular conduction ${ }^{1213}$ or an accessory pathway. ${ }^{14}$ The number of hospital admissions was greatly reduced and the need for drug treatment was virtually eliminated. Although similar long-term studies have not been reported for catheter ablation of accessory pathways, one would expect even greater savings in these patients because a permanent pacemaker is not required.

Used as described above, we believe that catheter ablation is an extremely valuable, minimally traumatic, and cost-effective tool for the management of arrhythmias. Because the 
option of surgical ablation is available we can use catheter ablation with caution, maximising its safety and allowing it to be used not only as a treatment of last resort.

\section{PHARMACOLOGICAL TREATMENT VERSUS NON-} PHARMACOLOGICAL TREATMENT

Most $(77 \%)$ patients in this study required no treatment or received drug treatment alone, guided by serial electrophysiological testing where appropriate. However, this global figure masks a trend away from pharmacological treatment over the past few years, and over $30 \%$ of patients now receive one or other form of non-pharmacological treatment. Increasingly we are turning away from pharmacology and towards attempting to cure arrhythmias with ablation or to palliate them with devices that we hope are more cost-effective than drug treatment. It is unfortunate that we are not in a position to compare the efficacy and cost-effectiveness of pharmacological and non-pharmacological treatments, and it will be a prime requirement to attempt to make such judgements when our new information systems are in place. Meanwhile, resource limitations (both in terms of laboratory time and device funding) will be the principal limitation on our use of non-pharmacological treatment strategies. The present data indicate that the limit lies at around $30-35 \%$ of all patients referred for invasive electrophysiological study.

Clearly drug treatment may be more expensive over the lifetime of a patient but the expense is spread out over years. Non-pharmacological treatment, particularly device implantation, is much more expensive initially and then much less expensive as time goes by. It is therefore more cost-effective if the patient survives for a long period, but the initial outlay is much greater and provision for costing and comparing such contrasting treatments needs to be made to enable referring physicians to make an informed and sensible choice.

\section{ELECTROPHYSIOLOGICAL PROCEDURES IN THE} CONTEXT OF GENERAL CARDIOLOGICAL CARE It would have been interesting to examine the referral patterns of patients for invasive electrophysiological procedures within our hospitals and their relation to the advances in treatment and also to the clinical outcome of these patients; however, with the exception of patients who had ablation, antitachycardia pacemakers and implantable cardioverter/ defibrillators, clinical outcome data were not available, nor were retrospective referral patterns. All of these data will be available prospectively, however, with the introduction of new administrative and clinical computing systems in 1990-92; it will then be possible to assess the true impact on clinical outcome, quality of life, and cost-effectiveness of different treatments for cardiac arrhythmia.

Until then this present review indicates that the demand for invasive electrophysiological procedures within our hospitals continues to increase, and the resumption of this increase in 1991 after artificially imposed restrictions in 1989-90 shows little tendency for the curve to flatten out. It may well be that the clinical need for these procedures exceeds the services provided nationally in the United Kingdom and that the number of procedures that we are able to perform will therefore always remain resource-limited. If that is the case, and provided cost-effectiveness can be demonstrated, then consideration should be given to increasing the availability of these services, both by training more cardiac electrophysiologists and by providing a larger number of specialist centres with facilities to provide all of these treatments.

1 Scheinman MM, Morady F, Hess DS, Gonzalez R. Catheter-induced ablation of the atrioventricular junction to control refractory supraventricular arrhythmias. JAMA 1982;248:851-5.

2 Cunningham D, Rowland E, Rickards AF. A new low energy power system for catheter ablation. $P A C E$ 1986;9: energy pow.

3 Ahsan AJ, Cunningham D, Rowland E, Rickards AF. Catheter ablation without fulguration: design and performance of a new system. PACE 1989;12:1557-61.

4 Warin J-F. Catheter ablation of accessory pathways: technique and results in 248 patients. PACE 1990;13:1609-14.

5 Huang SK, Bharati S, Graham AR, Lev M, Marcus FI, Odell RC. Closed-chest catheter ablation of the atrioventricular junction using radiofrequency energy: a new tricular junction using radiofrequency energy: a new method of cathe

6 Cunningham D. High energy catheter ablation of cardiac arrhythmias: an outmoded technique in the 1990s. Clin Cardiol 1991;14:595-602.

7 Lee MA, Morady F, Kadish A, et al. Catheter modification of the atrioventricular junction with radiofrequency energy for control of atrioventricular nodal reentry tachycardia. Circulation 1991;83:827-35.

8 Calkins H, Sousa J, El-Atassi R, et al. Diagnosis and cure of the Wolff-Parkinson-White syndrome or paroxysmal supraventricular tachycardia during a single electrophysiological test. N Engl J Med 1991;324:1612-8.

9 Haissaguerre M, Warin JF, Lemetayer P, Saoudi $N$, Guillem JP, Barn $\mathbf{P}$, Lemetayer $P$, Saloudi $\mathbf{N}$ Guillem JP, Blanchot $P$. Closed-chest ablation of retrograde conduction in patients with atrioventricula nodal reen

10 Jackman WM, Wang $\mathrm{X}$, Friday $\mathrm{KJ}$, et al. Catheter ablation of accessory atrioventricular pathways (Wolff-ParkinsonWhite syndrome) by radiofrequency current. $N$ Engl $J$ Med 1991;324:1605-11.

11 Kuck K-H, Schlüter M, Geiger M, Siebels J, Duckeck W. Radiofrequency current catheter ablation of accessory atrioventricular pathways. Lancet 1991;337:1557-61.

12 Kay GN, Bubien RS, Epstein AE, Plumb VJ. Effect of catheter ablation of the atrioventricular junction on quality of life and exercise tolerance in paroxysmal atria fibrillation. Am J Cardiol 1988;62:741-4.

13 Rosenqvist M, Lee MA, Moulinier L, et al. Long-term follow-up of patients after transcatheter direct curren ablation of the atrioventricular junction. J Am Coll Cardiol 1990;16:467-74.

14 de Buitleir M, Bove EL, Schmaltz S, Kadish AH, Morady F. Cost of catheter versus surgical ablation in the WolffParkinson-White syndrome. Am J Cardiol 1990;66: 189-92. 